\title{
La prueba ilícita en materia de libre competencia
}

\author{
Ignacio Oltra Gras*
}

\begin{abstract}
RESUMEN
El penúltimo inciso del literal n) del artículo 39 del Decreto Ley $N^{\circ} 211$ establece la llamada regla de exclusión en materia de libre competencia, al disponer que los resultados de las facultades investigativas duras de la Fiscalía Nacional Económica no podrán ser utilizados como medios de prueba en el procedimiento seguido ante el Tribunal de Defensa de la Libre Competencia cuando ella baya incurrido en ciertas causales de ilicitud. Considerando los escasos años que lleva vigente la norma y la poca profundidad con que se ha abordado este tema en la doctrina, el presente artículo tiene por objeto realizar un análisis procesal acerca de la configuración de la prueba ilícita en el Decreto Ley $N^{\circ} 211$, poniendo especial énfasis en aquella evidencia que se obtiene como consecuencia del ejercicio de diligencias intrusivas por parte de la Fiscalia Nacional Económica.
\end{abstract}

Prueba ilícita - regla de exclusión - medidas intrusivas - Fiscalía Nacional Económica

\section{Illegal evidence in Antitrust Law}

\begin{abstract}
Paragraph seven of literal $n$ ) of Article 39 of Decree Law $N^{\circ} 211$ establishes the exclusionary rule in Competition Law, providing that the results of the investigative powers of the Chilean Antitrust Agency (Fiscalia Nacional Económica) may not be used as means of evidence in the proceedings before the Chilean Antitrust Court (Tribunal de Defensa de la Libre Competencia) when the Agency incured in certain causes of wrongfulness. Considering the short period the rule has been in force and the few pages this issue has addressed in the doctrine, this article aims to make a procedural analysis of the subject of illegal evidence in Decree Law No. 211, with particular emphasis in the evidence obtained upon exercise of intrusive measures by the Chilean Antitrust Agency.
\end{abstract}

Illegal evidence - exclusionary rule - intrusive measures - Chilean Antitrust Agency

* Abogado. Licenciado en Ciencias Jurídicas y Sociales de la Universidad de Chile. Ayudante de los Departamentos de Derecho Civil y de Derecho Procesal de la Facultad de Derecho de la Universidad de Chile. Correo electrónico: ioltra@fne.gob.cl.

Artículo recibido el 30 de agosto de 2014 y aceptado para su publicación el 28 de agosto de 2015 . 


\section{INTRODUCCIÓN}

$\mathrm{N}$

uestro país, siguiendo la tendencia comparada, ha iniciado paulatinamente la reglamentación de un sistema tutelar de la libre competencia, creando una institucionalidad especializada que se integra, principalmente, por dos organismos: la Fiscalía Nacional Económica (en adelante, Fiscalía o FNE) y el Tribunal de Defensa de la Libre Competencia (en adelante, Tribunal o TDLC).

La defensa de la libre competencia se materializa en el rol persecutor y acusador de la Fiscalía, que en lo fundamental consiste en investigar conductas potencialmente anticompetitivas de los agentes económicos que tengan o puedan tener efectos tanto sobre los mercados relevantes en que tienen lugar como sobre otros mercados relacionados; y cuando a juicio de la FNE dichas indagaciones den cuenta de una conducta anticompetitiva, ellas se traducen en requerimientos que se presentan ante el TDLC.

Como se logra apreciar, la efectividad de este sistema depende en gran medida de la labor que la Fiscalía efectúe en la etapa de investigación. Por ello, parece ser que la única forma de dotar al país de una institucionalidad sólida en materia de defensa y promoción de la libre competencia en los mercados se concretiza otorgándole a la FNE más y mejores herramientas y facultades investigativas, que le permitan realizar su trabajo de modo más expedito y eficiente.

Recogiendo estas necesidades, al comienzo de su primer mandato la actual presidenta Michelle Bachelet presentó un proyecto de modificación al Decreto Ley N 211 (en adelante, D.L. $\mathrm{N}^{\circ}$ 211) que, tras las modificaciones introducidas en el Congreso, dio lugar a la Ley 20.361, promulgada el 7 de julio de 2009 y que entró en vigor en octubre del mismo año.

Dicha reforma legal, entre otras materias, estableció dos importantes herramientas para lograr desmantelar carteles o acuerdos colusivos ${ }^{1}$ : la delación compensada y las medidas intrusivas de la FNE. Precisamente este último instrumento, las medidas intrusivas o facultades investigativas duras, constituye quizás la parte más sensible del estatuto en cuanto a las atribuciones de la $\mathrm{FNE}^{2}$.

El artículo 39 letra n) del D.L. N N $^{\circ} 11$ se refiere a ellas señalando que "[e]n casos graves y calificados de investigaciones destinadas a acreditar conductas de las descritas en la letra a) del artículo $3^{\circ}$, [el Fiscal Nacional Económico podrá] solicitar, mediante petición fundada y con la aprobación previa del Tribunal de Defensa de la Libre Competencia, autorización al Ministro de la Corte de Apelaciones que corresponda de

${ }^{1}$ Para efectos de delimitar el objeto de este trabajo, debemos precisar que se entiende por cartel o colusión toda práctica en la que ciertos competidores de un determinado mercado acuerdan, de manera ilegítima, subir precios, repartirse el mercado, bloquear el ingreso de nuevos competidores y afectar el resultado de procesos licitatorios. Véase: Tapia, J., "Carácter anticompetitivo de los acuerdos restrictivos de la competencia en el sector retail”. En Montt, P. y Nehme, N., Libre competencia y retail, Editorial Legal Publishing, Santiago, 2010, p. 121.

${ }^{2}$ Ferrada, F., La prueba ilícita en el sistema procesal civil, Abeledo Perrot - Legal Publishing, Santiago, 2011, p. 195. 
acuerdo al turno, para que Carabineros o la Policía de Investigaciones, bajo la dirección del funcionario de la Fiscalía Nacional Económica que indique la solicitud, proceda a:

n.1) Entrar a recintos públicos o privados y, si fuere necesario, a allanar y descerrajar;

n.2) Registrar e incautar toda clase de objetos y documentos que permitan acreditar la existencia de la infracción;

n.3) Autorizar la interceptación de toda clase de comunicaciones, y

n.4) Ordenar a cualquier empresa que preste servicios de comunicaciones, que facilite copias y registros de las comunicaciones transmitidas o recibidas por ella" (el destacado es nuestro).

Evidentemente, las herramientas descritas constituyen diligencias intrusivas, pues en sí mismas lesionan derechos fundamentales reconocidos por nuestra Constitución Política de la República (en adelante, Constitución o CPR). De allí que resulte del todo razonable que sea un órgano jurisdiccional quien autorice previamente la ejecución de este tipo de medidas para que se entiendan legitimadas en esta sede. En palabras de Ferrada, "se reconoce que hay una vulneración de un derecho fundamental, pero se acepta la transgresión y se admite su resultado, bajo ciertos parámetros o condiciones preestablecidos por el ordenamiento jurídico"3.

Dentro de este contexto es donde surge por primera vez en materia de libre competencia la problemática de la prueba ilícita, es decir, aquella que ha sido "obtenida con inobservancia de garantías fundamentales" 4 . Efectivamente, a pesar de que el texto del D.L. $\mathrm{N}^{\circ} 211$ no hace una referencia literal a esta figura, los últimos tres párrafos de la letra n) parecen establecer ciertas causales de ilicitud probatoria, cuyo elemento en común estaría dado por la existencia de una evidencia recogida por la FNE con vulneración de garantías fundamentales, pero que no cuenta con la legitimación legal necesaria para ello.

Con lo anterior en mente, este trabajo buscará responder la siguiente pregunta: ¿De qué forma nuestra legislación de defensa de la libre competencia reconoce y acoge la regla de exclusión del material probatorio obtenido con infracción de garantías fundamentales? Para resolver esta interrogante y efectuar una aproximación inicial al tema, se comenzará realizando un breve planteamiento del debate que surge a propósito de la evidencia de origen ilícito, explicando luego cuál es el fundamento que justifica la inutilización o pérdida de eficacia de la prueba al interior del procedimiento en un ámbito en el que los bienes jurídicos en juego son distintos a los que existen en las esferas donde comúnmente se estudia esta institución procesal. Enseguida se entregará una mirada general acerca de los supuestos en que la prueba ilícita recibe aplicación a raíz de las atribuciones investigativas de la Fiscalía, deteniéndonos en aquellos casos en que la preeminencia de poder de esta sobre los investigados invade de algún modo su esfera íntima. A continuación se tratará específicamente la hipótesis de exclusión

${ }^{3}$ Ibid., p. 196.

${ }^{4}$ Horvitz, M.I. y López, J., Derecho Procesal Penal Chileno, Tomo II, Editorial Jurídica de Chile, Santiago, 2002, p. 169. 
de las evidencias ilícitamente obtenidas por la FNE como consecuencia del ejercicio de sus facultades contenidas en la letra n) del artículo 39 del D.L. N 211: las diligencias intrusivas. Debido a la estrecha relación que ellas tienen con la institución que convoca esta investigación, se desarrollará de manera minuciosa todo lo relativo a sus causales de ilicitud probatoria y el procedimiento de reclamación a que están sujetas, haciendo propuestas destinadas a mejorar la actual regulación. Al respecto, parte importante de este análisis se centrará en el control que los órganos jurisdiccionales efectúan sobre estas potestades, ya sea de forma preventiva, mediante la doble autorización judicial que realizan el TDLC y el Ministro de turno de la Corte de Apelaciones (en adelante, MTCA), como de forma represiva, mediante las reclamaciones de los afectados ante el mismo tribunal unipersonal.

\section{Planteamiento General Del problema}

El denominado "debido proceso" constituye un principio rector del derecho procesal y de la actividad jurisdiccional del Estado, comprendiendo -entre otros- el derecho a la defensa, el mismo que a su vez incluiría el derecho a la prueba ${ }^{5}$. En general, la doctrina coincide en conceptualizar a este último como el derecho a que el juez admita, practique y valore la prueba realizada en el proceso, permitiendo que los resultados de la misma influyan en la convicción judicial ${ }^{6}$.

En nuestro sistema, ante la ausencia de una referencia explícita, puede sostenerse que el derecho a la prueba está recogido en el inciso $2^{\circ}$ del artículo $19 \mathrm{~N}^{\circ} 3$ de nuestra $\mathrm{CPR}$, al expresar que "toda persona tiene derecho a defensa jurídica en la forma que la ley señale”. Acerca de esto, es interesante la opinión de Carocca, quien considera que "[a]unque la intención de los redactores de estas normas fue la de limitar este reconocimiento a la defensa técnica o letrada, de su tenor literal se desprende que, en definitiva, el sentido de la garantía es mucho más amplio e incluye todos los aspectos que la doctrina y jurisprudencia internacional han caracterizado como comprendida en ella"7. Del mismo modo, estimamos que el derecho a la prueba estaría reconocido en el inciso $5^{\circ}$ de la misma disposición, como parte integrante de las exigencias de un racional y justo procedimiento.

Ahora bien, este derecho a valerse de pruebas en el proceso no es absoluto, porque exige el cumplimiento y respeto de ciertas formalidades y garantías que configuran los llamados "límites a la prueba". En efecto, como nos recuerda Carocca, "en la medida que

${ }^{5}$ Carocca, A., "Una primera aproximación al tema de la prueba ilícita en Chile" [en línea], En Ius et Praxis, Universidad de Talca, Vol. 4, No 2, 1998, en <http://www.redalyc.org/pdf/197/19740213.pdf > [consulta: abril de 2014 ] p. 302.

${ }^{6}$ Marinoni, L. G., Pérez, A., Núñez, R., Fundamentos del Proceso Civil. Hacia una teoría de la adjudicación. Abeledo Perrot - Legal Publishing, Santiago, 2010, pp. 280 y ss.

${ }^{7}$ Carocca, op. cit., p. 303. 
las garantías constitucionales forman parte de un sistema normativo, necesariamente han de tener límites, que derivan de la necesidad de respetar otros derechos fundamentales"

Estas limitaciones en relación a la proposición de medios probatorios han sido ordenadas acertadamente por Picó I Junoy ${ }^{9}$, quien distingue entre los límites extrínsecos y los intrínsecos. Los primeros corresponden a formalidades y requisitos procedimentales exigidos para presentar cualquier prueba. Por su parte, los segundos son aquellos presupuestos inherentes a la actividad probatoria, dentro de los cuales se encuentran la pertinencia, la utilidad y, por último, la licitud.

Así las cosas, pese a estar garantizado constitucionalmente, el derecho a la prueba dejaría de ser amparable cuando la rendición de los medios probatorios dentro del proceso se hiciere incumpliendo las formalidades legales, o se presentaren pruebas impertinentes, inútiles o -lo que nos interesa- ilícitas.

En este último caso, cuando se trata de elementos probatorios que tienen origen ilícito, el límite del derecho a la prueba vendría dado por el respeto de los demás derechos fundamentales como, por ejemplo, el derecho a la integridad física o psíquica, al honor y a la intimidad personal, a la inviolabilidad del domicilio y al secreto de las comunicaciones ${ }^{10}$.

En palabras de Jequier, el derecho a la prueba -o la actividad probatoria que de él se deriva- "debe ser ejercido, a la luz de los demás derechos esenciales que la misma Constitución le reconoce a las personas, en un plano de realización proporcionada y armónica de unos y otros. Dicho en otros términos, el justiciable no tendrá derecho alguno a la prueba en aquellos casos en que para obtenerla ha violentado determinados derechos fundamentales, pues, simplemente, en tales casos ese derecho no ha llegado siquiera a existir" ${ }^{11}$.

La consagración de la exclusión de la prueba ilícita como forma de otorgar una tutela efectiva dentro del proceso, surge debido a la necesidad de ponderar, por un lado, el derecho a recabar prueba de quien ha obtenido el medio probatorio objetado y, por el otro, los derechos fundamentales de aquel litigante contra el que se pretende hacer valer dicha evidencia.

Una colisión de intereses como esta plantea la recurrente tensión entre la eficacia y el garantismo.

Desde esta perspectiva, es indudable que la averiguación de los hechos constituye una actividad que encierra un interés público digno de protección; pero, como bien apunta Armenta, "resulta igualmente inapelable que dicha finalidad no puede conseguirse a toda

${ }^{8}$ Ibid., p. 305.

9 Picó I Junoy, J., "La prueba ilícita y su control judicial en el proceso civil”. En III Congreso Panameño de Derecho Procesal, Instituto Colombo Panameño de Derecho Procesal, Panamá, Agosto 2006, p. 160.

10 Picó I Junoy, J., El derecho a la prueba en el proceso civil, Ed. José María Bosch, Barcelona, 1996, pp. 39 y ss.

${ }^{11}$ Jequier, E., "La obtención ilícita de la fuente de la prueba en el proceso civil, Análisis comparativo del ordenamiento jurídico español y chileno” [en línea], En Revista Chilena de Derecho, Vol. 34, No 3, 2007 , en <http://www.scielo.cl/pdf/rchilder/v34n3/art06.pdf > [consulta: enero de 2015] p. 479. 
costa, y que el Estado no puede hacer dejación de su también función de garante de los derechos, singularmente de aquellos elevados a la categoría de derechos fundamentales"12.

La cuestión está lejos de ser pacífica. Efectivamente, para algunos, se debe privilegiar la búsqueda de la verdad dentro del proceso por sobre la protección de los derechos individuales, utilizando para esto último únicamente las herramientas que concede el derecho sustantivo; mientras que, para otros, se debe necesariamente aplicar la exclusión como forma de tutelar las garantías fundamentales que puedan verse afectadas.

A este respecto, adherimos a la solución esbozada por Ferrada, quien se inclina por favorecer la interpretación garantista de la ilicitud, en razón de los bienes jurídicos que protege. En este sentido, el autor considera "tolerable cierto margen de indefensión al desconocerse el derecho a la prueba, en pos de resguardar el debido proceso y los derechos fundamentales vulnerados en la recogida y rendición de prueba"13.

Bajo este marco, nuestro país ha desarrollado durante las últimas décadas una profunda transformación de sus instituciones procesales, situando a las garantías fundamentales en un lugar central dentro de la actividad jurisdiccional del Estado. Como parte de dichas garantías, podemos contar a la proscripción de la prueba ilícita, la que no ha sido nombrada como tal en la legislación nacional, sino que desde sus reformas se han ido estableciendo reglas de exclusión para privar de eficacia probatoria a los elementos que son recogidos o producidos con vulneración de garantías fundamentales ${ }^{14}$.

Con la entrada en vigencia del Código Procesal Penal (en adelante, CPP) se dio el primer paso en la consagración de esta figura, camino que ha sido seguido por las modificaciones en materia de familia y laboral, por el Proyecto de Código Procesal Civil, y recientemente por el estatuto legal de libre competencia contenido en el D.L. No 211.

\section{FundAMENTO DE LA EXCLUSIÓN PROBATORIA EN SEDE}

\section{DE LIBRE COMPETENCIA}

En los tiempos que corren, y en el contexto de una sociedad que se complica vertiginosamente, el Estado se ve obligado a potenciar ciertas áreas de intervención en busca de proteger el interés de la colectividad, principalmente en materia económica. El nuevo rol del Estado trae consigo una ampliación de su actividad vigilante, ya que debe tutelar el cumplimiento de la mayor cantidad de normas que dicta en ese sentido. La actividad a la que nos referimos se ha denominado "función inspectora de la Administración", que se define como aquella dirigida a velar por el ejercicio de los derechos y obligaciones por parte de un particular, con el fin de determinar su adecuación al ordenamiento

\footnotetext{
${ }^{12}$ Armenta, T., La prueba ilícita (un estudio comparado), Marcial Pons Ed., Madrid, 2009, p. 80.

${ }^{13}$ Ferrada, op. cit., p. 105.

${ }^{14}$ Así lo concluye Armenta, analizando la regulación penal chilena de la prueba ilícita. Véase: Armenta, op. cit., pp. 45-46.
} 
jurídico, para lo que incluye la recopilación de datos, la investigación y, en especial, la verificación del desarrollo ordenado de la actividad de la que el particular sea titular ${ }^{15}$.

Esta función del aparato administrativo se ha visto reforzada por el hecho de contar a su disposición con medios materiales y tecnologías ni siquiera imaginados hasta hace algunos años. Lo anterior es positivo en cuanto hace posible que la labor inspectiva se realice con mayor facilidad y en forma más efectiva, pero también acarrea el riesgo de que las investigaciones destinadas a controlar que la actividad de los particulares se ajuste a los fines de utilidad pública terminen por vulnerar los derechos fundamentales de los inspeccionados, como el derecho a la intimidad y la libertad económica ${ }^{16}$. En este sentido, es necesario ser extremadamente prudente y recordar que el límite entre la legítima intervención en pos de resguardar el bien común y la injerencia desmedida en la esfera de los particulares es muy tenue, lo que hace necesario delinear los alcances de este Estado capaz de ejercer un control demasiado invasivo sobre sus ciudadanos.

Desde la óptica del derecho de la libre competencia, el ejercicio de la potestad inspectora de la Administración le compete a la Fiscalía Nacional Económica, para ello ha sido dotada de las atribuciones investigativas que establece el artículo 39 del D.L. $\mathrm{N}^{\mathrm{o}} 211^{17}$.

En efecto, mediante la instrucción de las investigaciones que estime procedentes, la FNE puede verificar posibles infracciones a las normas contenidas en dicho estatuto, por lo que recabar información le resulta indispensable para el cumplimiento de su principal finalidad, requiriendo ante el TDLC cuando existan tales infracciones y actuando en ese proceso en representación del interés general de la colectividad en el orden económico. Ahora, junto con reconocer la conveniencia de estos poderes de inspección, no se puede dejar de observar, con el mismo énfasis, la necesidad de que su ejercicio por parte de la Fiscalía esté limitado dentro de contornos claros y precisos.

Al respecto, Agüero y Toro apuntan que "frente a argumentaciones de bien común o eficacia de la Administración en una investigación, deben tenerse en cuenta también los derechos y garantías que pueden chocar con dicha potestad, así como la posición jurídica que tiene el requerido de información en la investigación que se lleve a cabo por la FNE"18.

Así las cosas, el D.L. No 211 ha querido dar respuesta a esta necesidad de límites. Aunque el catálogo de atribuciones con que cuenta la Fiscalía parece otorgarle un poder casi absoluto para llevar adelante sus investigaciones, la verdad es que no es tan así, porque recientemente se han incorporado mecanismos de protección a favor de los sujetos pasivos de las mismas, algunos de estos tienen directa relación con la inutilización de la prueba recogida o rendida por medios ilícitos.

\footnotetext{
${ }^{15}$ García, A., La Potestad inspectora de las administraciones públicas, Marcial Pons Ed., Madrid, 2006, p. 29.

${ }^{16}$ Rivero, R., El Estado Vigilante. Consideraciones jurídicas sobre la función inspectora de la Administración, Editorial Tecnos, Madrid, 2000, pp. 121 y ss.

${ }^{17}$ Agüero, F. y Toro, L.E., "Límites a la potestad inspectora de la Administración: el caso de la Fiscalía Nacional Económica”, en Revista de Derecho Económico, Universidad de Chile, No 75, 2010, p. 25.

${ }^{18}$ Ibid., p. 33.
} 
Cuando hablamos de prueba ilícita en sede de libre competencia estamos presuponiendo la vulneración de un derecho fundamental en la actividad probatoria, pudiendo ocurrir en la fase previa al proceso judicial ante el TDLC o incluso dentro de él.

A continuación se deben determinar los efectos que esa vulneración debe tener al interior del procedimiento, para las partes y el juez, que pueden resumirse en la inutilización o pérdida de eficacia de la prueba. Sin embargo, antes de eso, creemos que corresponde preguntarse acerca de los fundamentos que justifican la aplicación de tales consecuencias en un ámbito en el que los bienes jurídicos en juego son distintos a los que existen en las esferas penal y civil, donde comúnmente se trata esta institución.

Efectivamente, en el caso del procedimiento sancionatorio del ámbito de la libre competencia, estamos ante la presencia de una autoridad administrativa -el Fiscal Nacional Económico- que, para comprobar las infracciones a la legislación que regula esta materia, tiene la posibilidad de encargar diligencias a Carabineros o la Policía de Investigaciones, pudiendo incluso solicitar algunas que vulneran directamente derechos fundamentales de los investigados (artículo 39 letra n) del D.L. No 211).

Por esta razón, adherimos a Ferrada, para quien el fundamento de la exclusión de la prueba ilícita en este campo, "atendida la evidente desigualdad de partes, y considerando que estamos frente a un aparato administrativo investigador premunido de fuertes poderes, creemos que debe ser el correcto actuar del órgano que busca la sanción, a quien se le dable [sic] exigir un comportamiento ético y apegado a la ley a fin de cumplir su objetivo" ${ }^{19}$. Esta ética y apego a la ley exigible a la FNE conlleva la necesidad de recordar que los derechos fundamentales de los investigados y los de quienes se quiere proteger con las investigaciones son igual de relevantes, por lo que hay que encargarse de velar por la protección de unos y otros con la misma fuerza.

En este punto, debemos tener en cuenta que la consagración de la posibilidad de exclusión de prueba en la sede que analizamos es relativamente nueva. Para ser más precisos, teniendo a la vista el original D.L. No 211, hasta hace pocos años se concluía que en este tipo de procedimientos no cabía la posibilidad de excluir material probatorio por infracción de garantías fundamentales. Lo anterior se veía reforzado por el hecho de que el estatuto se remitía -y se remite- a las reglas generales del Código de Procedimiento Civil (en adelante, CPC), en el que tampoco existe reglamentación al respecto ${ }^{20}$.

Según se ha entendido, la razón por la que se plantea el problema de la prueba ilícita en materia de libre competencia se explica con la promulgación de la Ley 20.361, ya que, previo a ella, el D.L. N 211 no contemplaba hipótesis asimilables a las contenidas en el actual artículo 39 letra n). Por cierto, dicha disposición estableció, en su centro, poderosas herramientas para lograr desmantelar carteles, las facultades investigativas duras o intrusivas de la FNE, cuyo ejercicio constituye la manifestación más clara del posible conflicto que puede darse entre el interés del Estado y el de los privados.

${ }^{19}$ Ferrada, op. cit., p. 200.

${ }^{20}$ Distinto va a ser el caso eventual en que se acojan las modificaciones al actual CPC, que sí contemplan una audiencia preliminar para excluir la prueba ilícitamente obtenida. 
Específicamente, el otorgamiento de estas atribuciones impuso la necesidad de crear un control jurisdiccional para llevarlas a cabo, pues con ellas existía un alto riesgo de lesionar derechos fundamentales de los investigados. Es, en definitiva, con la consagración del aludido mecanismo de control externo de ilicitud que surge por primera vez en este ámbito una regulación de la institución procesal que nos ocupa, cuyo objeto, así como veremos luego, consiste en evitar que en el procedimiento seguido ante el TDLC se utilicen evidencias obtenidas ilegítimamente por la Fiscalía en su labor investigativa.

\section{IV. Ámbitos de APLICACión de LA PRUEBa ILÍCITA EN EL D.L. Nº 211}

Como se ha expuesto, la cuestión concerniente a la prueba lícita en sede de competencia es un tema que se volvió importante en nuestro país con la entrada en vigencia de la Ley 20.361. No obstante, ha hecho fuerza la idea de que la violación de los derechos fundamentales también puede tener lugar a propósito de otras facultades investigativas de la Fiscalía, siempre que la preeminencia de poder de esta sobre los perseguidos invada de algún modo su esfera íntima.

Para cumplir con los objetivos precisos que el ordenamiento jurídico le ha encomendado a la FNE, el artículo 39 del D.L. No 211 se encarga de consagrar las potestades y atribuciones con las que cuenta el Fiscal Nacional Económico, así como los recursos humanos y materiales de que se encuentra dotada. En lo que sigue, señalaremos brevemente en cuáles de estas atribuciones podemos encontrar supuestos de aplicación de la prueba ilícita.

En primer lugar, las letras f) y g) de dicha norma facultan al Fiscal para requerir la información relevante que exista en los archivos de funcionarios públicos y empleados de empresas públicas y sociedades del Estado, indicando expresamente el legislador que ellos estarán obligados a entregarla, incluso cuando los antecedentes estén calificados como secretos o reservados, pero en este caso se exigirá la autorización previa del TDLC.

Así, se reconoce la existencia de un límite al ejercicio de esta potestad, materializado por medio de una fórmula de control de carácter eventual y preventiva; eventual, pues únicamente se activa cuando la información solicitada haya sido declarada como secreta o reservada por ley, y preventiva, porque el control del Tribunal debe preceder a la solicitud de información. Bajo el supuesto de que se haya omitido esta autorización, sería posible solicitar la exclusión de los antecedentes que se obtengan en virtud de uno de estos requerimientos como medio de prueba.

Respecto de las solicitudes de antecedentes que contengan información que no haya sido calificada como secreta o reservada, si bien esta disposición no lo regula de forma explícita, igualmente podría caber la inutilización de la prueba aplicando el procedimiento del artículo 11 bis de la Ley 18.575, Orgánica Constitucional de Bases Generales de la Administración del Estado. Conforme a este, el jefe superior del órgano requerido puede, por resolución fundada, denegar el acceso a los antecedentes solicitados cuando ello afecte sensiblemente el interés de terceros que se hayan opuesto a su entrega, circunstancia en la que cabría su exclusión en el eventual juicio. En este caso, así como en 
el anterior, la justificación de la pérdida de eficacia de la prueba vendría dada por una conculcación del derecho fundamental a la privacidad en la obtención de la información.

En segundo lugar, la letra h) concede a la Fiscalía la facultad para solicitar a los particulares, ajenos a la Administración del Estado, la información y antecedentes que estime necesarios con motivo de las investigaciones que practique.

Ahora, debido a la evidente amplitud de la potestad ${ }^{21}$, el literal "contempla también el derecho de los requeridos para solicitar al TDLC que se deje sin efecto total o parcialmente la solicitud del Fiscal, para el caso en que la entrega de la información "pudiere irrogar perjuicios a sus intereses o a los de terceros"" 22 . Dentro de las causales que permitirían fundar el ejercicio de este derecho de oposición -y la posterior exclusión de prueba- podemos encontrar el resguardo de información sujeta a cláusulas de confidencialidad $^{23}$ y la protección de datos de carácter personal ${ }^{24}$, entre muchas otras.

En tercer lugar, la letra j) establece otro ámbito que podría dar lugar a la inutilización, al autorizar al Fiscal para citar a declarar o solicitar declaración por escrito a entidades o personas que pudiesen tener conocimiento de las conductas investigadas o que hubiesen participado en estas.

Es importante tener presente que el procedimiento de investigación instruido por la FNE debe adecuarse de forma rigurosa a las exigencias del artículo $19 \mathrm{~N}^{\circ} 3$ de nuestra Constitución. Conforme a ellas, el que las investigaciones se desarrollen de manera racional y justa importa que en todas sus etapas debe procurarse siempre e irrenunciablemente no afectar ni lesionar los derechos fundamentales de los inculpados, como tampoco de quienes se vean afectados por ellas ${ }^{25}$. Atendido lo anterior, los derechos de estos podrían verse gravemente lesionados si las declaraciones que toma la FNE se tornan especialmente invasivas, como por ejemplo, siendo prestadas bajo alguna forma de coacción física o psicológica, hipótesis en que sobrarían argumentos para solicitar la exclusión de dicha declaración como material probatorio del juicio.

Lamentablemente, las disposiciones que hemos analizado hasta aquí (letras f), g), h) y j)) guardan silencio en cuanto a la vía para reclamar del vicio de ilegalidad. Esta omisión podría frustrar las expectativas de los investigados que pretendan evitar que

${ }^{21}$ Al respecto, Agüero y Toro sostienen: "La redacción de la habilitación legal de la FNE para ejercer la potestad inspectora evidencia un problema habitual en estas materias: no existe precisión en la norma que autoriza, la que en definitiva permite a la FNE pedir cualquier información y antecedentes ('que estime necesarios'), sin que deba justificar la necesidad de estos. O bien, podemos decir la norma es precisa y permite pedir cualquier información de los particulares". Véase: Agüero y Toro, op. cit., p. 28.

${ }^{22}$ Ibíd., p. 29.

23 Tribunal de Defensa de la Libre Competencia, resolución de fecha 18 de abril de 2007, [en línea] <http://www.tdlc.cl/DocumentosMultiples/Art.\%2039\%20h)_Resolucion_11_2007.pdf>[consulta: 12 de mayo de 2014].

${ }^{24}$ Tribunal de Defensa de la Libre Competencia, resolución de fecha 29 de diciembre de 2008, [en línea] <http://www.tdlc.cl/DocumentosMultiples/Art.\%2039\%20h)_Resolucion_25_2008.pdf> [consulta: 12 de mayo de 2014].

${ }^{25}$ Cea, J. L., Derecho Constitucional Chileno. Derechos, Deberes y Garantías, Tomo II. Editorial Universidad Católica de Chile, Santiago, 2004, p. 159. Citado en: Agüero y Toro, op. cit, p. 32. 
el Tribunal tome contacto con el material contaminado, sin entregar herramientas para paliar sus efectos.

Al no existir una norma especial en el D.L. N ${ }^{\circ} 211$-ni en el estatuto supletorio del CPC-, suscribimos a la opinión que señala que debe preferirse la exclusión de la prueba ilícita, previa solicitud de parte realizada por la vía incidental ordinaria ${ }^{26}$.

En lo relativo a la tramitación del incidente, como en este procedimiento no existe una fase preparatoria de discusión acerca de la admisibilidad de la prueba, será preferible que el TDLC lo resuelva en un momento anterior a la incorporación del material viciado al expediente de juicio y, en caso de llegar a la convicción de que existe ilicitud, debiera optar por la sanción de la no valoración de dicha prueba, de manera de evitar, en lo posible, contaminar su convencimiento jurisdiccional respecto del fondo de la cuestión controvertida.

En cuarto lugar, y por último, nos encontramos con las facultades contenidas en la letra $n$ ): las medidas intrusivas de la FNE.

Debido a la estrecha relación que ellas tienen con la institución que nos convoca, todo lo relativo a las causales de ilicitud, su procedimiento de reclamación y el control jurisdiccional a que están sujetas, será materia de estudio en la siguiente sección.

\section{Medidas intrusivas y EXClusión de prueba ilícita}

Se ha dejado establecido que son varios los ámbitos donde la prueba ilícita recibe aplicación dentro del D.L. N $\mathrm{N}^{\circ} 211$, pero en ninguno de ellos su vínculo con los derechos individuales es tan nítido como ocurre con las herramientas investigativas establecidas en el literal n) de su artículo 39.

Dicha disposición habilita al Fiscal para solicitar, en casos calificados y siempre que se acredite que se dispone de antecedentes precisos y graves acerca de la existencia de prácticas colusivas, el ejercicio de facultades de allanamiento, incautación o interceptación de comunicaciones, previa autorización concedida por el TDLC y un MTCA.

En esencia, se trata de diligencias intrusivas, pues son potencialmente lesivas de los derechos fundamentales de los investigados.

En razón de lo anterior, "[s]i lisa y llanamente se llevaran a cabo por un órgano administrativo, habría que convenir que su legalidad o más bien su constitucionalidad sería impensable. Empero, se entienden legitimadas en sede de libre competencia cuando son autorizadas por un órgano jurisdiccional" 27 . En otras palabras, el sistema admite que exista una vulneración de esta clase de derechos, aunque solo en un ámbito delimitado y bajo condiciones preestablecidas por el estatuto orgánico de la FNE.

No obstante, es necesario advertir que la legitimidad de la transgresión de un derecho o garantía fundamental no se satisface simplemente con la constatación de ciertos

\footnotetext{
${ }^{26}$ Ferrada, op. cit., p. 160.

${ }^{27}$ Ferrada, op. cit., p. 196.
} 
requisitos formales; toda medida restrictiva de derechos ha de ser racional y justificada, debiendo superar el test de ponderación entre los perjuicios causados y los beneficios esperados por ella.

Al respecto, en cuanto a la necesidad y exigencia de fundamentación de la diligencia, muy ilustrativo es lo señalado por el Tribunal Constitucional español: "[c]uando se coarta el libre ejercicio de los derechos reconocidos por la Constitución el acto es tan grave que necesita encontrar una especial causalización y el hecho o conjunto de hechos que lo justifican deben explicarse con el fin de que los destinatarios conozcan las razones por las cuales su derecho se sacrificó y los intereses a los que se sacrificó. De este modo, la motivación no es solo una elemental cortesía, sino un riguroso requisito del acto de sacrificio de los derechos" 28 .

\section{Causales de ilicitud de prueba}

Actualmente se coincide en no permitir la admisibilidad y posterior apreciación de la prueba ilícitamente obtenida, de manera que la incorporación en nuestro sistema procesal de libre competencia del nuevo literal n) en el artículo 39 constituye un verdadero acierto de modernidad legislativa.

Sin embargo, aunque dicha norma viene a resolver expresamente la discusión acerca de la admisión o no de la prueba ilícita en este ámbito, su redacción deja un importante espacio para el debate relativos al alcance de los supuestos de exclusión.

Como bien identifica Ferrada ${ }^{29}$, los últimos tres incisos de la letra n) parecen disponer las causales de ilicitud probatoria en relación con el resto de la norma. Haciendo un desglose, las hipótesis construidas por el legislador para excluir la prueba ilícitamente obtenida serían cuatro:

1.1. En caso que la Fiscalía no cumpliere con alguno de los requisitos o formalidades indicados en el párrafo cuarto del literal n).

La primera de las hipótesis dice relación con la prueba proveniente de actuaciones o diligencias en cuyo desarrollo el Fiscal no haya cumplido con los requisitos mencionados en el inciso $4^{\circ}$ de la letra $n$ ), disposición que se remite expresamente a las reglas formales establecidas en el CPP, al expresar: "El ejercicio de las facultades conferidas en el párrafo primero, deberá sujetarse a los requisitos y formalidades establecidos en los artículos 205; 207; 208; 209, incisos primero, segundo y tercero, no siendo aplicable la remisión de los antecedentes al fiscal regional, para los efectos previstos en este último inciso; 210; 212 a 214, 216 a 225, salvo el inciso tercero del artículo 222, del Código Procesal Penal [...]”. Por consiguiente, todos los requisitos establecidos en la

28 Tribunal Consatitucional (España), Sentencia No 26, de 17 de julio de 1981. Citada en: HerreroTejedor, F., Legislación y jurisprudencia constitucional sobre la vida privada y la libertad de expresión, Editorial Constitución y Leyes, Madrid, 1998, p. 52.

${ }^{29}$ Ferrada, op. cit., pp. 197-198. 
normativa procesal penal que no evidencien contradicción con la regulación especial del D.L. N $^{\circ} 211$ tienen plena aplicación, de modo que cualquier desviación que observe la FNE respecto de ellos da derecho a las partes investigadas para solicitar su exclusión como material probatorio.

Un ejemplo claro de esta hipótesis podría plantearse si se realizaran interceptaciones telefónicas en una investigación que no las hiciere especialmente imprescindibles, con lo que se pasaría a llevar el requisito indicado en el artículo 222, inciso $1^{\circ}$, del CPP. Esta norma hace referencia a la ponderación de proporcionalidad a la que somete el órgano jurisdiccional la procedencia de esta medida intrusiva, lo que importa que la FNE deba ajustarse al estándar que se le exige al Ministerio Público, acreditando que no existe ningún otro método menos gravoso para el afectado que logre satisfacer los fines del procedimiento sancionatorio.

1.2. En caso que el desempeño o ejercicio de las actuaciones hubiere tenido lugar fuera de los supuestos establecidos en la ley.

La segunda causal de ilicitud se refiere a los antecedentes obtenidos en virtud de facultades intrusivas que se han impetrado apartándose de los supuestos legales. Al respecto, el primer inciso del literal n) describe precisamente los supuestos de hecho bajo los cuales el Fiscal puede solicitar este tipo de diligencias, al señalar que ellas solamente tendrán lugar " $[\mathrm{e}] \mathrm{n}$ casos graves y calificados de investigaciones destinadas a acreditar conductas de las descritas en la letra a) del artículo $3^{\circ}$, vale decir, conductas colusorias.

Parece inobjetable, entonces, que debe proceder la exclusión probatoria cuando la actividad de la Fiscalía haya tenido por finalidad la acreditación de cualquier tipo de ilícito contrario a la libre competencia que no se adecue a la descripción que realiza el artículo $3^{\circ}$ letra a) del D.L. $\mathrm{N}^{\circ} 211$, como sucede, entre otras prácticas, con los abusos unilaterales de posición dominante.

1.3. En caso que no se hubieren cumplido los requisitos previstos para la procedencia de las actuaciones.

La tercera hipótesis de prueba ilícita apunta a aquellos casos en que las medidas llevadas adelante por la FNE no se encuentren legitimadas por las exigencias preestablecidas por el legislador. En específico, la principal exigencia formal que el Fiscal debe cumplir para que procedan las actuaciones del literal n) consiste en contar con la autorización de un MTCA, la que debe ser requerida mediante petición fundada y con la aprobación previa del TDLC. Para complementar este control jurisdiccional, el inciso $4^{\circ}$ ordena que la resolución judicial que autorice una actuación intrusiva especifique "con precisión, la singularización de las medidas, el tiempo por el cual podrán ejercerse y las personas a las que dichas medidas pueden afectar".

Estos requisitos constituyen verdaderas garantías que buscan resguardar de manera efectiva el debido proceso; por tanto, la omisión de alguna de las autorizaciones judiciales señaladas habilita a los afectados para solicitar la declaración de inutilización de las 
pruebas obtenidas mediante este tipo de facultades. Si, por ejemplo, le bastase a la FNE con la sola aprobación previa del TDLC, se produciría un incentivo perverso a favor de la Administración, ya que se le permitiría ejercer una diligencia que vulnera derechos fundamentales de los investigados, pero sin el control del tribunal llamado justamente a velar por ellos, lo que es de suyo intolerable.

1.4. En caso que los antecedentes que se obtengan en virtud del ejercicio de las facultades sean utilizados por la Fiscalía en otra investigación, sin que medie una nueva autorización judicial.

La última de las causales de ilicitud de prueba está contenida en el inciso final de la letra $n$ ), el que dispone que si con motivo del ejercicio de una medida intrusiva se obtuvieren antecedentes que no hayan estado siendo investigados con anterioridad a la solicitud, la Fiscalía tiene la obligación de pedir una nueva autorización judicial para que esta nueva información pueda ser utilizada en otra investigación distinta.

La obtención de antecedentes en estas circunstancias da forma a lo que la doctrina ha llamado "hallazgos casuales", cuestión que nos parece especialmente relevante a propósito de las hipótesis de exclusión probatoria. El problema de esta figura dice relación con la obtención de "[...] resultados probatorios derivados de la realización de determinadas diligencias encaminadas en un principio a la investigación de un determinado delito, pero de las que resultan elementos que acreditan la existencia de otro delito distinto o afectante a un tercero no inicialmente investigado" ${ }^{30}$. En consecuencia, se trata de contenidos irrelevantes para el procedimiento dentro del cual se obtienen, por lo que el debate se centra en determinar su admisibilidad o inadmisibilidad como material probatorio de cargo.

El literal examinado, considerando el grave menoscabo a los derechos fundamentales que implican las diligencias intrusivas, estableció una prohibición expresa y absoluta de utilización del material constitutivo de los hallazgos casuales en una investigación distinta de la que dio origen a la medida, excepto cuando el órgano jurisdiccional competente revisare nuevamente los requisitos establecidos para la autorización de estas diligencias y acceda a una nueva solicitud de la Fiscalía en tal sentido ${ }^{31}$.

Debido a que el presupuesto de la norma es que los antecedentes obtenidos no pueden ser utilizados en la "otra investigación" a menos que medie la autorización judicial, la petición de la FNE debería explicitar cuál es ella y satisfacer, de manera completamente independiente de las solicitudes y autorizaciones originales, todos los requisitos formales y sustantivos que exige la letra n). Una actuación que se aparte de cualquier modo del

30 Álvarez de Neyra, S., "Los descubrimientos casuales en el marco de una investigación penal (con especial referencia a las diligencias de entrada y registro en domicilio)" [en línea], En Revista Internacional de Estudios de Derecho Procesal y Arbitraje, N $\mathrm{N}^{\circ}$ 2, 2011, en <http://www.riedpa.com/COMU/documentos/ RIEDPA21101.pdf> [consulta: abril de 2014], p. 4.

${ }^{31}$ Esta nueva autorización debieran prestarla los órganos jurisdiccionales previstos por el D.L. N 211 para las solicitudes originales, es decir, tanto el TDLC como el MTCA. 
proceder anteriormente descrito devendrá en ilícita, y con ella, el material obtenido, el que deberá ser excluido como antecedente o elemento probatorio del juicio.

En otras palabras, la FNE está legalmente facultada para utilizar hallazgos casuales, previa autorización judicial, solo si se refieren a un conjunto determinado de hechos que se encuentren cubiertos por la configuración que haya realizado el propio órgano de la Administración en su solicitud. Pero no puede utilizarlos si se trata de conductas diferentes o de diversos afectados en sus derechos fundamentales, incluso cuando se trate, en abstracto, de la misma conducta constitutiva de una infracción a la letra a) del artículo $3^{\circ}$ del D.L. N 211.

A pesar de lo equívoca que puede ser la redacción del literal n), por cuanto aparentemente se trata de hipótesis de ilicitud que responderían a necesidades distintas, lo cierto es que en todos los casos que hemos revisado el requisito indispensable para que se excluya la prueba obtenida es que ella se haya recopilado mediante una ilegalidad que, además, se encuentre revestida de una entidad mayor, manifestada en el hecho de devenir en consecuencias graves de afectación de los derechos fundamentales del sujeto pasivo de la diligencia.

La raíz común, entonces, está dada por la existencia de una medida intrusiva que infringió esta clase de derechos, pero que se apartó del supuesto de justificación que establece la ley para que pueda tener lugar. Esto no es más que el reconocimiento de lo preceptuado por los artículos 6 y 7 de la CPR, en relación con la actuación de los órganos del Estado, en el caso que revisamos, el Fiscal Nacional Económico.

La falta de legitimidad para la lesión de derechos fundamentales es la que autoriza, en última instancia, la inutilización de los antecedentes obtenidos por la FNE en virtud de sus facultades duras.

\section{Procedimiento de exclusión probatoria}

Como ya adelantamos, en nuestro sistema procesal de libre competencia la ineficacia de la prueba ilícita aparece legalmente reconocida en la letra n) del artículo 39 como un problema que afecta la admisibilidad de los resultados de las diligencias intrusivas. Según veremos, será un tribunal externo al fondo del litigio el encargado de declarar la ineficacia de la prueba, pudiendo ser luego revisada su denegación por la vía del recurso de reclamación ante la Corte Suprema (en adelante, CS).

En primer término, la regla que hace operativa en esta sede la inadmisibilidad de la prueba ilícitamente obtenida se encuentra consagrada en los incisos $6^{\circ}$ y $7^{\circ}$ del literal en comento, los cuales facultan a los afectados por las medidas para reclamar ante el mismo Ministro de turno de Corte de Apelaciones que las haya autorizado en caso que la FNE haya incurrido en alguna de las causales de ilicitud probatoria que hemos señalado.

Respecto de la tramitación de esta reclamación, la disposición simplemente señala que el tribunal "resolverá de forma inmediata, en una sola audiencia, sin forma de juicio y oyendo a las partes".

Luego, y en el evento que el MTCA resuelva a favor de los afectados, la norma indica que los resultados obtenidos por la Fiscalía con motivo del ejercicio de las facultades 
intrusivas no podrán ser utilizados como medios de prueba en los requerimientos que se sustancien ante el TDLC. Se trata, pues, de evitar que los jueces encargados de resolver el fondo del asunto emitan un veredicto contaminados por la influencia del material de origen ilícito.

De acuerdo con la doctrina autorizada en la materia, la reclamación del vicio de ilicitud constituye un incidente especial de exclusión, y la resolución que lo falla, una sentencia interlocutoria que produce el efecto de cosa juzgada para el procedimiento seguido ante el Tribunal ${ }^{32}$. En virtud de lo anterior, y considerando que el legislador en este caso no excluyó expresamente el recurso de apelación en contra de las resoluciones que dicte el MTCA al conocer acerca de materias en el contexto del literal n) del artículo 39, es posible sostener que aquellas serán apelables ante la Corte de Apelaciones (en adelante, CA) que corresponda, conforme a las reglas generales y al principio de doble instancia consagrado en el artículo 187 del CPC.

La primera observación que arroja la norma transcrita es que se echa de menos un mayor desarrollo del procedimiento de exclusión.

Efectivamente, aun estando en juego el libre ejercicio de los derechos fundamentales de los individuos, la disposición señala que las reclamaciones por infracciones de los requisitos establecidas en resguardo de dichos derechos deben resolverse "de forma inmediata, en una sola audiencia, sin forma de juicio y oyendo a las partes", lo que pareciera dejar al juez privado de un plazo razonable para verificar, evaluar y ponderar lo expuesto por las partes, y a estas de la oportunidad de allegar antecedentes en apoyo de sus pretensiones, esto incumple el deber constitucional que recae sobre el legislador de establecer siempre las garantías de un procedimiento y una investigación racionales y justos, en contravención a lo dispuesto en el numeral $3^{\circ}$ del artículo 19 de la CPR.

El problema podría subsanarse de raíz si se estructurara el debate del proceso en dos audiencias distintas, una de examen de admisibilidad de la prueba ofrecida ante el MTCA y otra de juicio propiamente tal ante el TDLC, de manera similar a como sucede en el actual procedimiento penal, donde la exclusión es químicamente más pura.

La ventaja de establecer una audiencia preparatoria o preliminar es que "permite efectuar de una sola vez, con una visión global y omnicomprensiva, la determinación de las pruebas que se rendirán" ${ }^{33}$, otorgándole a las facultades intrusivas de la FNE un correlato en materia de garantías para los particulares. Aunque la implementación de este sistema exige una reforma legislativa mayor, el TDLC igualmente tendría que incorporar estos conceptos en sus procedimientos. De este modo, se sugiere que, en los supuestos en que se presente una reclamación y mientras ella no sea resuelta por parte del MTCA, debería optarse por suspender el procedimiento respecto de todas las diligencias probatorias que puedan estar contaminadas o viciadas con la prueba cuya validez se disputa ante el dicho juez. Por ejemplo, las absoluciones de posiciones y audiencias

\footnotetext{
${ }^{32}$ Ferrada, op. cit., p. 199.

${ }^{33}$ Ibid., p. 111.
} 
testimoniales en las que eventualmente puedan ser exhibidos los registros de audio de las interceptaciones telefónicas que sean objeto de una reclamación.

Por su parte, también es criticable que la norma no sea del todo clara en cuanto a la oportunidad procesal que tienen los afectados para reclamar del vicio de ilicitud, pues ello los deja en un estado de incerteza jurídica.

En este ámbito, nos sumamos al parecer de Ferrada, para quien la regla general, respecto de los medios de prueba que no sean instrumentos, es que la solicitud de exclusión pueda presentarse hasta el vencimiento del término probatorio, porque el artículo 22 del D.L. N 211 le otorga un carácter fatal a dicho plazo. Por excepción, en cuanto a los instrumentos, el plazo vencería diez días antes de la fecha que haya fijado el TDLC para la vista de la causa, ya que de acuerdo al inciso $8^{\circ}$ del artículo 22 ese es el momento hasta el cual se puede presentar la prueba instrumental ${ }^{34}$.

En último término, volviendo al resto de la regulación, puede perfectamente suceder que el MTCA resuelva en contra de los solicitantes acerca de la declaración de inutilización, admitiendo que sea rendida en el juicio una prueba que se sostiene ha sido ilícitamente obtenida. En este evento, los afectados podrían interponer el recurso de reclamación ante la CS respecto de la sentencia definitiva que se dicte en aquel procedimiento, fundado en que se han infringido sustancialmente las disposiciones relativas a la exclusión probatoria contempladas en el literal n) del artículo 39.

De procederse de esta forma, será el máximo tribunal de nuestro país el que tendrá la última palabra en cuanto a cuál es el equilibrio entre el interés general en materia de libre competencia y la protección de los derechos fundamentales de los perseguidos.

\section{Control de la Corte de Apelaciones y rol del Tribunal de Defensa de la Libre Competencia}

Avanzado ya el análisis respecto de las causales de ilicitud probatoria a propósito de las diligencias intrusivas y el procedimiento de reclamación a que ellas están sometidas, es admisible preguntarse acerca de cuáles van a ser las consecuencias directas de la inobservancia de garantías fundamentales en la recopilación o rendición de la evidencia por parte de la FNE.

Como se podría esperar, la principal consecuencia que esa vulneración debe tener al interior del proceso, para las partes y el TDLC, puede resumirse en la inutilización o pérdida de eficacia de la prueba, "esto es, que el elemento que fue obtenido de manera antijurídica no llegue a tener influencia en el juez al momento de dictar sentencia, ni se vea reflejado directa o indirectamente en esta" ${ }^{35}$.

Lo cierto es que dicha ineficacia puede manifestarse, en principio, en momentos procesales distintos: uno inicial, en la admisión del elemento probatorio obtenido; y otro final, durante su apreciación judicial, esto es, en la emisión del juicio jurisdiccional ${ }^{36}$.

\footnotetext{
${ }^{34}$ Ibid., p. 200.

${ }^{35}$ Ferrada, op. cit., p. 108.

${ }^{36}$ Ibid., pp. 107 y ss.
} 
Así, entonces, quedan planteadas las dos clases de sanciones respecto de la prueba ilícita, su exclusión y su no valoración ${ }^{37}$.

Al respecto, el penúltimo inciso del literal n) es categórico al disponer que "[1]os resultados de las actuaciones establecidas en el párrafo primero no podrán ser utilizados como medios de prueba en el procedimiento ante el Tribunal", cuando el Ministro de Corte de Apelaciones de turno declare que la FNE ha caído en alguna de las causales de ilicitud probatoria del literal n) (el destacado es nuestro).

Esta prohibición expresa de utilizar los elementos recogidos ilegalmente, declarada así por un juez que no entra a conocer del fondo del asunto, permite concluir que nuestro legislador manifiesta una preferencia por establecer el control de la prueba ilícita al nivel de la admisibilidad, sancionándola con su exclusión, con el fin de evitar que el TDLC llegue a tener mayor conocimiento respecto de aquel material. Lo anterior, como expresan Horvitz y López, “conlleva impedir que el órgano jurisdiccional encargado de adoptar la decisión de absolución o condena conozca de manera alguna el elemento de prueba obtenido mediante la actividad ilícita" 38 .

De esta forma, el incidente de exclusión ventilado ante el MTCA resulta ser la oportunidad legal por excelencia para controlar la licitud de la prueba en la jurisdicción de libre competencia ${ }^{39}$.

Atendido lo expuesto, la determinación del rol del TDLC ante la prueba ilícita no parece compleja en el evento que el tribunal unipersonal resuelva excluirla, pues, en tal caso, "[e]l efecto que tendrá esa declaración es que no puede entrar a la vista de la causa la fuente de prueba objeto de la inutilización, ni menos puede hacerse valer en la sentencia definitiva. Pero para que ello ocurra, se debe prohibir tajantemente que dicha fuente conste de cualquier manera en el expediente o carpeta" ${ }^{40}$.

Ahora bien, la pregunta que se plantea es que si el D.L. N 211 reconoce como sanción a la prueba ilícita únicamente su exclusión, omitiendo hablar de no valoración,

${ }^{37}$ En el ámbito comparado, la decisión de implementar una u otra sanción depende en gran medida de la forma en que se estructure el procedimiento. Tomando como referencia la situación del proceso penal, Armenta señala que "[l]a exclusión tiene mucho que ver, asimismo, con el tratamiento procesal que reciba la prueba ilícita: si este se ubica en la fase investigadora, la consecuencia de su apreciación será la eliminación absoluta del proceso, de manera que el órgano juzgador ni llegará a conocer de su existencia. No siendo así o negándose tal radicalidad, podrá examinarse al inicio del juicio o al dictar sentencia; en el primer supuesto aún cabría su exclusión, en el segundo, los efectos se limitan a no poder ser valorada para fundamentar una eventual condena”. Véase: Armenta, op. cit., p. 90.

${ }^{38}$ Horvitz, y López, op. cit., p. 178.

39 Considerando que la inadmisión permitiría suprimir totalmente los efectos del acto probatorio contaminado, no es de extrañar que la generalidad de la doctrina la califique como la sanción principal. Véase: López Barja de Quiroga, J., Las Escuchas Telefónicas y la Prueba Ilegalmente Obtenida, Ediciones Akal, Madrid, 1989, p. 131; y Picó I Junoy, El derecho a la prueba..., op. cit., pp. 94-95. De hecho, algunos autores nacionales han afirmado tajantemente que "la inadmisibilidad de la prueba es la única posición que tiene un verdadero efecto probatorio, porque resulta imposible pretender que el tribunal, después de conocido el elemento de prueba, no vea afectada su convicción por el solo hecho de haberse informado de la existencia de ese elemento. Véase: Horvitz, y López, op. cit., 179.

${ }^{40}$ Ferrada, op. cit., p. 199. 
pueda estimarse que esta sea una alternativa viable y aplicable. Dicho de otro modo, si puede o no el TDLC, en la sentencia definitiva, negarse a valorar la evidencia -que no ha sido previamente declarada inadmisible por el MTCA ante una reclamación-, por estimar que se trata de prueba ilícita y, por tanto, inutilizable para poder fallar el asunto.

En particular, este delicado tema ha sido latamente discutido en materia penal, existiendo opiniones en uno y otro sentido.

Un sector de la doctrina, que podríamos calificar de minoritario, le niega al Tribunal de Juicio Oral en lo Penal (en adelante, TJOP) la posibilidad de restarle valor a la prueba considerada por este como ilícita. Entre ellos, Tavolari afirma que el TJOP no puede permitir que se plantee un "debate sobre el rechazo de prueba ya aceptada por el juez de garantía, o sobre su licitud, previamente admitida por dicho juez o, finalmente sobre cualesquiera otra mención del auto" ${ }^{1} 1$ de apertura del juicio oral. El mismo criterio comparten Horvitz y López, para quienes este "fenómeno solo acarrea efectos negativos para el sistema: la audiencia de juicio oral debe asumir la carga de recibir, no ya solo la prueba de los hechos que fundamentan la acusación y la defensa, sino también la prueba sobre la licitud de la prueba $[\ldots . . .42$; ; en este sentido, añaden, "la conclusión obvia es que, declarada erróneamente admisible la prueba ilícita por el juez de garantía, la vía natural para renovar la discusión sobre ese punto es la interposición del correspondiente recurso de nulidad en contra de la sentencia definitiva dictada con fundamento en la prueba ilícita rendida ante el tribunal del juicio oral. La necesaria valoración de la prueba ilícita por parte del tribunal del juicio oral es así un presupuesto indispensable para que el recurso de nulidad sirva a este propósito, conforme a lo previsto por el art. 375 CPP” 43.

En la vereda contraria, sin embargo, se ha asentado como postura predominante la idea de que el TJOP no está obligado a reconocerle valor a la prueba ilícita que ha sido admitida erróneamente por el Juez de Garantía en el auto de apertura del juicio oral, sino que, muy por el contrario, está facultado siempre para no valorarla, como una forma de corregir el primer razonamiento incorrecto. Uno de los más notables exponentes de esta tesis es Hernández, quien considera inadmisible "entender que el tribunal de juicio oral se encuentra absolutamente atado por el auto de apertura en términos tales que no solo está obligado a recibir la prueba ilícita, sino que también a valorarla y eventualmente a dictar sentencia con fundamento en ella, haciendo total abstracción de una ilicitud que no le corresponde a él declarar" ${ }^{4}$. Este autor llega a afirmar que el artículo 276 del CPP cumpliría en nuestro ordenamiento la función de una prohibición general de valoración, invocándola como sustento para la posición que habilita al TJOP

41 Tavolari, R. "Informe en Derecho: Del debate sobre la licitud de la prueba y su exclusión por parte del tribunal de juicio oral y procedencia legal de consignar en la sentencia de juicio oral las decisiones relevantes adoptadas en la audiencia”. En Boletín del Ministerio Público, No 14, Santiago, marzo 2003. Citado en: Ibid., p. 116.

42 Horvitz, y López, op. cit., p. 201.

43 Ibid., p. 203.

${ }^{44}$ Hernández, H., "La exclusión de la prueba ilícita en el nuevo proceso penal chileno”, En Colección de Investigaciones Jurídicas de la Escuela de Derecho de la Universidad Alberto Hurtado, No 2, 2002, p. 90. 
para omitir la valoración de la prueba ilícitamente obtenida, al momento de dictar la sentencia definitiva, bajo pretexto de ilicitud ${ }^{45}$. En consecuencia, "[c]ualquier otra interpretación implicaría sostener un supuesto deber de los jueces de fallar conscientemente con fundamento en la vulneración de garantías fundamentales" ${ }^{46}$. En la misma dirección, se pronuncia Carocca ${ }^{47}$.

En materia de libre competencia, en cambio, el problema relativo a si el TDLC está autorizado o no para suprimir la valoración de la prueba rendida ante él, bajo el argumento de considerarla ilícita, no ha sido tratado por la doctrina. Por de pronto, su solución no puede ser una cuestión pacífica, tomando en cuenta que la propia ley ha previsto el órgano jurisdiccional específico ante el cual se debe formular la solicitud de exclusión, pero sin constituir a dicha instancia en una audiencia preliminar como tal en que se valore integralmente la prueba.

El D.L. N 211 no contempla ninguna norma de carácter general que autorice al Tribunal para negarle valor a la prueba ilegalmente obtenida, como sí sucedería en materia penal de acuerdo con el parecer de Hernández ${ }^{48}$. Es más, según revisamos, el énfasis del aludido estatuto está centrado en conseguir la exclusión probatoria con anterioridad a la vista de la causa, justamente para evitar cualquier reflejo en la sentencia de los efectos del material contaminado ${ }^{49}$.

No se puede discutir que la exclusión de prueba ilícita en el incidente de reclamación referido constituye la situación óptima, pero también es innegable que cuando esa situación no se configura nada debiese obstar a recrear la discusión ante el tribunal juzgador ${ }^{50}$. A nuestro entender, el hecho de que el estatuto establezca la exclusión como sanción a la prueba ilícita no significa que se debe descartar la no valoración del TDLC como una de las soluciones subsidiarias para concretar la inutilización y lograr el pleno respeto de las garantías fundamentales lesionadas en la obtención de aquella prueba. Muy lejos de eso, la no valoración llevada a cabo por el Tribunal debe ser uno más de los controles que deben aplicarse en el procedimiento ${ }^{51}$.
45 Ibid.
46 Ibid.
${ }^{47}$ Carocca, A., "La prueba en el nuevo proceso penal". En AA.VV., El nuevo proceso penal, Cuadernos de trabajo, Universidad Diego Portales, No 2, 2000, p. 192.

48 Hernández, op. cit., p. 90.

49 Como admite Picó I Junoy, "[1]a exigencia ex lege de que la prueba ilícita no surta efecto alguno comporta, en opinión de la mayoría de los autores, la necesidad de retirar del proceso todo vestigio de la misma, devolviéndosela al litigante que la aportó”. Véase: Picó I Junoy, El derecho a la prueba ..., op. cit., p. 333.

${ }^{50}$ Es más, puede darse el supuesto de que la ilicitud se produzca incluso al momento de rendir la prueba ofrecida ante el TDLC, caso en el que la prohibición de valoración debe necesariamente utilizarse como una sanción subsidiaria a la exclusión. Véase: Miranda, M., El concepto de la prueba ilícita y su tratamiento en el proceso penal, $2^{a}$ Ed., Ed. José María Bosch, Barcelona, 2004, pp. 99-100.

${ }^{51}$ En la misma dirección se ha pronunciado el Tribunal Supremo español, en sentencia de fecha 20 de enero de 2007, recaída en un asunto contencioso de libre competencia, al declarar que "el derecho a utilizar los medios de prueba pertinentes para la defensa [...] excluye la admisibilidad y apreciación de pruebas ilícitas". 
El cuadro que se produce cuando la prueba ilícita queda en una situación tal dentro de la vista de la causa que amarra al Tribunal a resolver el asunto conforme a ella es preocupante. Nos parece que la sola posibilidad de imponerle a los jueces de fondo la obligación de valorar y fallar sobre la base de evidencias que a sabiendas se obtuvieran con infracción de garantías fundamentales, al menos pone en tela de juicio los supuestos efectos negativos que le acarrearía al sistema el permitirle al TDLC restarle valor a la prueba. Por esta razón, apunta Ferrada, y "pese al silencio que pueda haber en los estatutos, se debe entender siempre facultado el juez para no valorar la prueba ilícita" ${ }^{2}$.

En estos casos, el Tribunal de fondo conocerá de la prueba obtenida con infracción de garantías fundamentales, pero, alegada la ilicitud de la misma y habiendo convicción sobre ello, dicha prueba no podrá ser valorada ni considerada para dictar sentencia.

Resulta claro, entonces, que el dilema "no es si confiar en la no valoración como solución a la ilicitud, sino evitar que el ordenamiento descanse en ella como el único medio destinado a combatirla, ya que las posibilidades de influencia sobre los otros medios de prueba se ven aumentadas. Si existe un doble control, a nivel de inadmisión en la etapa intermedia y de no valoración en el juicio, sin duda que aumenta la posibilidad de evitar los efectos de la fuente contaminada en la sentencia, dando mayor protección a los derechos fundamentales" 53 .

En suma, una vez rechazada la alegación de ilicitud de la prueba en el respectivo incidente especial de exclusión, al afectado no le quedará más que emprender el controvertido rumbo de replantearlo ante el TDLC o esperar que se dicte la sentencia definitiva para recién ahí procurar configurar una causal que amerite el recurso de reclamación para ante la CS. En cualquier caso, lo resuelto por el MTCA no será vinculante para ninguno de estos tribunales, los que podrán perfectamente negarle valor a la prueba que estimen que se ha obtenido incurriendo en alguna causal de ilicitud.

\section{Conclusiones}

En cualquier ámbito en que se estudie, la pérdida de eficacia de la prueba ilícita supone la imposibilidad de admitirla y valorarla, esto es, su inutilización en el proceso. De la revisión que se ha hecho de esta institución en nuestra jurisdicción de libre competencia, resulta incuestionable que su consagración merma las posibilidades de averiguación y esclarecimiento de los hechos objeto del procedimiento, ello es reflejo de una ideología jurídica comprometida con principios superiores y en virtud de esto se piensa que ese esclarecimiento no puede ser alcanzado a cualquier precio, en particular al de vulnerar derechos fundamentales de los investigados.

Sin duda, la entrada en vigor de la Ley 20.361, con la consecuente incorporación de la regla de exclusión al procedimiento regulado en el D.L. N N $^{\circ} 11$, respondió a esta

\footnotetext{
${ }^{52}$ Ferrada, op. cit., p. 116.

${ }^{53}$ Ibid., 124.
} 
nueva ideología. Precisamente con el fin de evitar eventuales lesiones a los derechos fundamentales de los perseguidos, dicha modificación legal, junto con otorgar a la Fiscalía poderosas facultades investigativas para desmantelar carteles -que incluyen entrar, allanar o descerrajar lugares cerrados, registrar papeles y documentos, o interceptar comunicaciones-, se preocupó de reglarlas en términos precisos y estrictos, indicando los requisitos para poder utilizar la prueba obtenida con motivo de su ejercicio y estableciendo ciertos mecanismos de control jurisdiccional.

En específico, aunque la redacción del legislador no fue del todo clara, hemos podido constatar que el literal n) del artículo 39 creó un novedoso procedimiento de reclamación frente a ciertas hipótesis de ilicitud, en virtud de ello los afectados por las medidas intrusivas pueden dirigirse ante el MTCA que originalmente las hubiere autorizado y solicitarle que declare que los antecedentes que resulten de ellas no puedan ser utilizados como medios de prueba por la Fiscalía. Según vimos, las causales legales que autorizan a los afectados para presentar esta reclamación vienen señalados en los últimos tres incisos de la misma letra, a saber: (i) cuando la FNE no cumpla con los requisitos o formalidades señalados en el inciso $4^{\circ}$, (ii) cuando el desempeño o ejercicio de las medidas haya tenido lugar fuera de los supuestos establecidos en la ley, (iii) cuando no se hayan cumplido los requisitos previstos para la procedencia de las facultades y (iv) cuando los antecedentes obtenidos en virtud de las medidas sean utilizados en otra investigación, sin que medie una nueva autorización judicial.

A esta altura, es menester reiterar que la sanción de exclusión asignada a la prueba ilícita en la forma regulada en el D.L. No 211 es, a nuestro juicio, insuficiente. Efectivamente, si bien resulta ser un gran avance en la materia que la declaración de inutilización la realice un juez que no entra a conocer del fondo del litigio, el TDLC de algún modo igualmente se verá afectado o contaminado por los antecedentes obtenidos en virtud de las diligencias intrusivas. Por tal razón, es imposible que el Tribunal no conozca de estas pruebas antes de que se resuelva acerca de su ilicitud, porque, al no existir una audiencia preliminar, recién con la presentación del requerimiento y la consecuente exhibición del expediente investigativo los afectados podrán conocer las circunstancias en que se llevaron a cabo las medidas intrusivas y, posteriormente, reclamar ante el aludido MTCA. De esta forma, no existe seguridad en cuanto a que el TDLC no forme su convicción a base del medio probatorio ilícito presentado, el que podría influir inevitablemente en su decisión.

Asimismo, no deja de llamar la atención que, aunque la letra n) del artículo 39 puntualiza el derecho que tienen los afectados para presentar reclamaciones ante un tribunal unipersonal externo cuando se trata del ejercicio de facultades especialmente invasivas, esas potestades son únicamente algunas de las que tiene la FNE, agotándose las medidas de protección para los investigados en estas facultades altamente especiales. Nada se dice, en cambio, respecto del derecho a defensa de los particulares que sean citados a prestar declaraciones ante funcionarios de la FNE (letra j)), ni de la posibilidad de entender aplicable el derecho a guardar silencio que pudiera verse violado frente a los requerimientos de información (letra h)). Tampoco hay un régimen de cautela de garantías como el del artículo 10 del CPP, ni menos un catálogo de derechos procesales. 
Lo anterior evidencia la necesidad de que el estatuto se haga cargo de estas deficiencias y que, en especial, reconozca una fórmula general de exclusión de la prueba ilícita, recibiendo aplicación por medio de un procedimiento único y frente a cualquiera de las facultades de investigación con las que cuenta la Fiscalía, y no solo las del literal n).

Si bien aún es muy apresurado para sacar conclusiones categóricas, considerando los escasos años que lleva vigente la Ley 20.361, las resoluciones del MTCA y posteriormente de la propia CA serán cruciales para delinear jurisprudencialmente esta materia. En este sentido, parece lógico que cada vez que la FNE utilice sus facultades duras para fundar requerimientos no se haga esperar la reacción de los requeridos, quienes cuestionarán su uso con las respectivas reclamaciones, verificando rigurosamente el cumplimiento de todos los requisitos de licitud para establecer los límites a su debido ejercicio.

Estimamos, finalmente, que el esfuerzo por regular esta institución en sede de libre competencia ha quedado en deuda. No se pueden negar sus aciertos, pero hubiese sido deseable una mayor precisión a la hora de implementar la exclusión como la vía para lograr la inutilización del material probatorio ilícitamente obtenido. Solo queda esperar que nuestro legislador haga eco de esta situación, ampliamente advertida en el presente artículo, y reforme las normas que requieran una mejora. El debido resguardo de los derechos fundamentales lo hace imprescindible.

\section{BIBLIOGRAFÍA}

Agüero, F. y Toro, L. E., "Límites a la potestad inspectora de la Administración: el caso de la Fiscalía Nacional Económica”, En Revista de Derecho Económico, Universidad de Chile, $\mathrm{N}^{\circ} 75,2010$.

Álvarez de Neyra, S., "Los descubrimientos casuales en el marco de una investigación penal (con especial referencia a las diligencias de entrada y registro en domicilio)" [en línea], En Revista Internacional de Estudios de Derecho Procesal y Arbitraje, No 2, 2011, en <http://www. riedpa.com/COMU/documentos/RIEDPA21101.pdf> [consulta: abril de 2014].

Armenta, T., La prueba ilícita (un estudio comparado), Marcial Pons Ed., Madrid, 2009.

BofILl, J., "La prueba en el proceso penal", En Revista de Derecho y Jurisprudencia, Tomo XCI, $\mathrm{N}^{\circ} 1$, Enero 1994.

Bofill, J., "Informe en Derecho", En causa Rol 886-2012, seguido ante el Ministro de turno de la Corte de Apelaciones de Santiago, 11 de junio de 2012.

Carocca, A., "Una primera aproximación al tema de la prueba ilícita en Chile" [en línea], En Ius et Praxis, Universidad de Talca, Vol. 4, No 2, 1998, en <http://www.redalyc.org/ pdf/197/19740213.pdf > [consulta: abril de 2014].

Carocca, A., "La prueba en el nuevo proceso penal". En AA.VV., El nuevo proceso penal, Cuadernos de trabajo, Universidad Diego Portales, No 2, 2000.

Ferrada, F., La prueba ilícita en el sistema procesal civil, Abeledo Perrot, Santiago, 2011.

García, A., La Potestad inspectora de las administraciones públicas, Marcial Pons Ed., Madrid, 2006.

GonZÁlez, A., "Prácticas colusivas", En Tribunal de Defensa de la Libre Competencia (editores), La libre competencia en el Chile del bicentenario, Thomson Reuters PuntoLex, Santiago, 2011.

Hernández, H., "La exclusión de la prueba ilícita en el nuevo proceso penal chileno", En Colección de Investigaciones Jurídicas de la Escuela de Derecho de la Universidad Alberto Hurtado, № 2, 2002. 
Herrero-Tejedor, F., Legislación y jurisprudencia constitucional sobre la vida privada y la libertad de expresión, Editorial Constitución y Leyes, Madrid, 1998.

Horvitz, M.I. y López, J., Derecho Procesal Penal Chileno, Tomo II, Editorial Jurídica de Chile, Santiago, 2002.

Jequier, E., "La obtención ilícita de la fuente de la prueba en el proceso civil. Análisis comparativo del ordenamiento jurídico español y chileno" [en línea], En Revista Chilena de Derecho, Vol. 34, No 3, 2007, en <http://www.scielo.cl/pdf/rchilder/v34n3/art06.pdf > [consulta: enero de 2015].

López Barja De Quiroga, J., Las Escuchas Telefónicas y la Prueba Ilegalmente Obtenida, Ediciones Akal, Madrid, 1989.

Marinoni, L.G., Pérez, A., Núñez, R., Fundamentos del Proceso Civil. Hacia una teoría de la adjudicación. Abeledo Perrot - Legal Publishing, Santiago, 2010.

Miranda, M., El concepto de la prueba ilícita y su tratamiento en el proceso penal, $2^{\mathrm{a}}$ Ed., Ed. José María Bosch, Barcelona, 2004.

Picó I Junoy, J., El derecho a la prueba en el proceso civil, Ed. José María Bosch, Barcelona, 1996.

PICó I Junoy, J., "La prueba ilícita y su control judicial en el proceso civil”, En III Congreso Panameño de Derecho Procesal, Instituto Colombo Panameño de Derecho Procesal, Panamá, Agosto 2006.

Rivero, R., El Estado Vigilante. Consideraciones jurídicas sobre la función inspectora de la Administración, Editorial Tecnos, Madrid, 2000.

TAPIA, J., "Carácter anticompetitivo de los acuerdos restrictivos de la competencia en el sector retail”. En Montt, P. y Nehme, N., Libre competencia y retail, Editorial Legal Publishing, Santiago, 2010.

Zapata, M.F., La prueba ilícita, Editorial Lexis Nexis, Santiago, 2004. 